\title{
An Investigation on Post-Disaster Housing Resident Satisfaction in Subaşı After the Marmara Earthquake
}

\section{Alper Bodur}

Ondokuz Mayıs University, Faculty of Architecture, Ilkadım, Samsun, 55100, Turkey

Corresponding author: boduralper@yandex.com

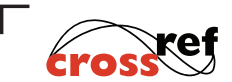

http://dx.doi.org/10.5755/j01.sace.26.1.22465
This paper is the result of a survey that aims to learn the perceptions and evaluations of the people living in permanent residences after the Marmara Earthquake. In doing so, it guides the decision-makers and researchers about the features that should be in the planning stage of permanent residences and to bring out some points that they should take into account in the future. Within the extent of the study, permanent houses which have been built in Subaşı Village, Yalova, Turkey have been analyzed in the meaning of post-earthquake housing applications after the Marmara earthquake on 17 August 1999. In the research, the planning of the houses built in Subaşı Village, the overall evaluations about the design, the principles of entitlement, the planning method of the permanent houses, and the demographic features of the householders are evaluated. For this reason, a questionnaire was created to understand the thoughts of the respondents. In this sense, users' satisfaction was examined through the survey which based on interviews with the householders. Within the questionnaire, the users have answered some questions such as demographic characteristics, economic conditions, and the degree of previous house satisfaction, the physical, social, environmental features of the permanent houses, social relations, and general perceptions. In doing this, users were asked to evaluate the positive and negative aspects of the project.

One of the most critical problems in the area is transportation. On the other hand, problems have also emerged in the social relations of people settled in permanent residences after a physically destructive earthquake. In general, participants have definite opinions about the houses on earthquake resilience, size, and location of residential interiors, visual privacy, and lighting. Also, they have negative notions about auditory privacy, heating, transportation to the city center, relations with relatives, problemsolving with neighbors, municipal services. As a result of the research, it is observed that the permanent residential areas in Subaşı could not unite with the existing city. The findings suggest that the permanent residences in the research area produced for the people who suffered from the earthquake have not been able to meet the needs of the households sufficiently. Besides, looking at the results of the study from a broad perspective, it is necessary to evaluate the subject holistically so that the permanent houses do not create new problems for the despairing households.

Keywords: earthquake, post-disaster housing, residential satisfaction.
JSACE $1 / 26$

An Investigation on Post-Disaster Housing Resident Satisfaction in Subaşı After the Marmara Earthquake

Received 2019/07/29

Accepted after revision 2020/01/17

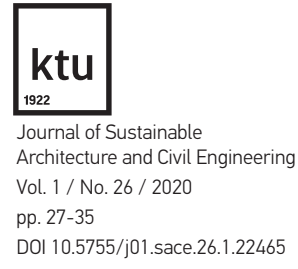


Introduction

Fig. 1

The position of regions corrupted on 17 August Marmara Earthquake (Source: Kadıoglu, 2005)
Turkey is one of the countries suffering from earthquakes concerning its geological and topographical features (Limoncu and Bayulgen, 2005). The country has had 285 medium and large quakes in which 100,000 people missed their lives, 170,000 people were wounded, and 650,000 housing has experienced severe destruction within the years 1900-2010 (Pampal and Ozmen, 2015; Yamalı et al., 2015). The most devastating one was an earthquake which emerged on 17 August 1999 in the Marmara Region of Turkey. The quake provoked a tremendous loss of life and assets, corrupted the social and financial structures of the country in an almost irreparable way and gained its way into one of the most devastating earthquakes of history records (Oztekin and Yıldırım, 2015). According to the Turkish Prime Ministry Crisis Management Center, the earthquake caused the death of 17.479 people and 43,953 wounded (Ozmen, 2000).

The centers of İstanbul, Kocaeli, Sakarya, Bolu, Bursa, Zonguldak, Eskişehir and Yalova provinces influenced significantly by the quake (Tas et al., 2011). The earthquake further damaged 213,843 housing blocks which are the most significant number of dwelling units demolished by an earthquake in the devastated areas in Turkey (Ganapati, 2013). Fig. 1 shows the position of regions corrupted on 17 August Marmara Earthquake.

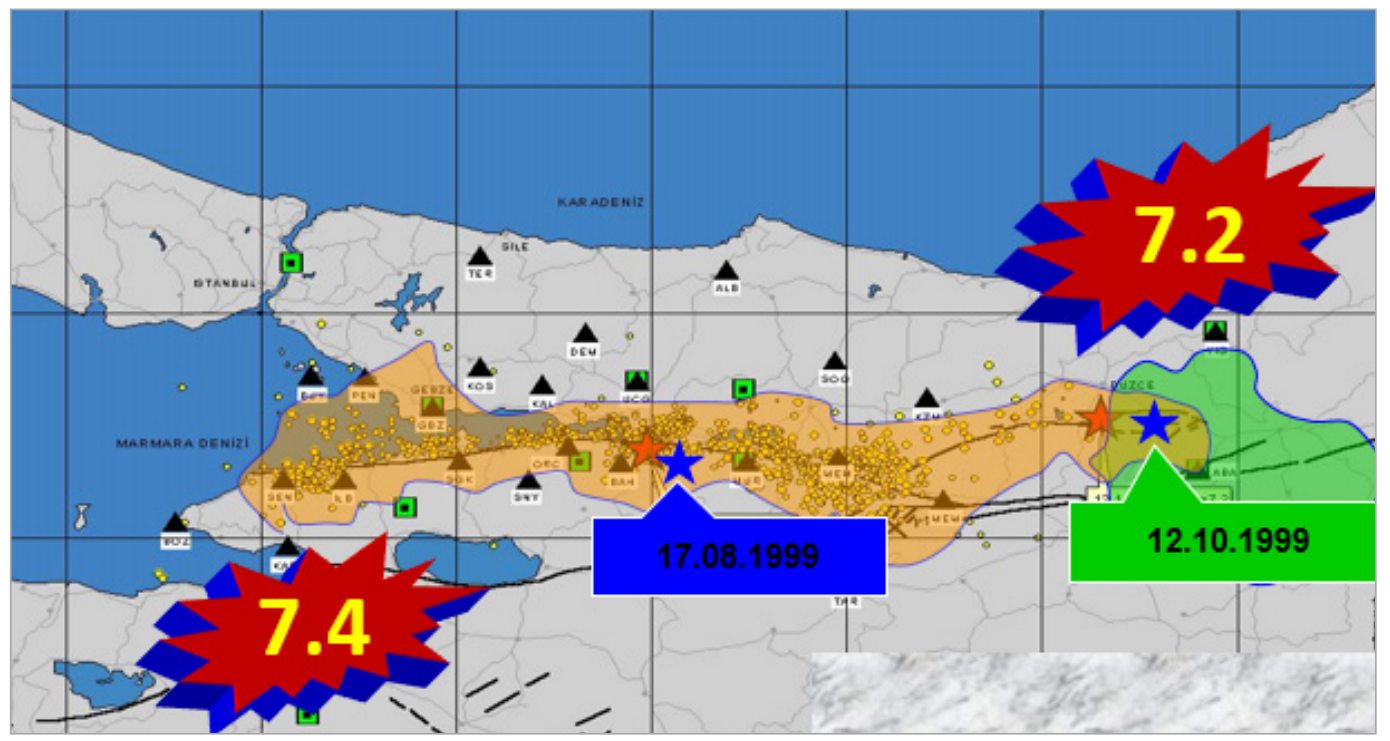

However, many problems come into being. The people whose houses demolished or heavily damaged had some problems such as economic, social, housing etc. For instance, the government built many permanent houses in the Marmara Region. Indeed, all over the world, the states reveal various methods to cope with the housing problem which occurs after earthquakes (Tas et al., 2007). According to Federal Emergency Management Agency (1998), there are four distinct extending phases after disasters in the housing improvement method: (1) spontaneous shelter (first 72 hours), (2) emergency shelter (first 60 days), (3) temporary housing (first year and beyond) and (4) permanent housing FEMA, 1998). The short and long-term housing recovery is thus a crucial viewpoint of post-disaster rebuilding (Freeman, 2004; Mukherji, 2015).

Permanent housing is the last stage to afford long-term permanent housing solutions for disaster victims (FEMA, 1998). Permanent housing, post-disaster housing, in other words, is named by United Nations (1982) as housing policies and applications following a disaster for joining the urgent, temporary and permanent sheltering requirements of the survivors of the disaster (UN, 1982). Another definition of post-disaster housing by the Disaster and Emergency Management Authority of Turkey (AFAD) is that it is a lawful residence built by state or particular organizations for those who experienced radical destruction from disasters (AFAD, 2014). 
Permanent houses are not houses constructed in a very different way from those produced before the quake. Nevertheless, one of the most significant exceptions is that post-disaster housing is built very fast and supports to respond to the regular way of living situations. As it should be in residential buildings manufactured under natural circumstances, many factors such as cultural, environmental and economic factors should be planned in post-disaster housing.

Permanent houses are to build for the psychologically, culturally and economically affected people whose expectations of the built environment in which they will live for an extended period as well as fitting the housing needs (Tas et al., 2007). Within the extent of the study, permanent houses which have been built in Subaşı Village, Yalova, Turkey have been analyzed in the meaning of post-earthquake housing applications after the Marmara earthquake on 17 August 1999. Furthermore, overall evaluations are made about the satisfaction of the houses before the quake, the plan and construction phases of the permanent houses, the demographic features of the participants. Within the context, this article aims to guide the decision-makers and researchers about the features that should be in the planning stage of permanent residences and to bring out some points that they should take into account in the future.

In the study, it is aimed to learn the perceptions and evaluations of the people living in permanent residences after the Marmara Earthquake about their permanent residences. The field of the study is the permanent residences built in Subaşı Village, Yalova regarding that Yalova was the place where the loss of life and property was the most intense after the earthquake of August 17, 1999. The sample was randomly chosen from the dwellings.

The questionnaire was created to understand the feelings of the householders. After selecting the sample and designing the questionnaire, a total of 17 face-to-face interviews were started. Although the sample size seems to be relatively small, the findings provide sufficient statistical information about the overall satisfaction of the respondents.

Within the questionnaire, the users have answered some questions such as demographic characteristics, economic conditions, the degree of previous house satisfaction, the physical, social, environmental features of the permanent houses, social relations, and general perceptions. In doing so, users were asked to evaluate the positive and negative aspects of the project. As aforementioned, the case study area is Subaşı permanent residences in Yalova province which is located in the east shoreline of Marmara Sea. Fig. 2 shows the location of Subaşı permanent residences site plan. As the smallest city in Turkey with a complete area of $847 \mathrm{~km}^{2}$ (Marka, 2010), it is influenced by the seismic moves towards the forearms of the North Anatolian fault band (Url-1).

Following the 1999 Marmara quake, 2,504 people died, and 6,042 people were injured in Yalova. 9.462 houses and 727 workplaces severely; 7.917 houses and 1.036 workplaces moderately;
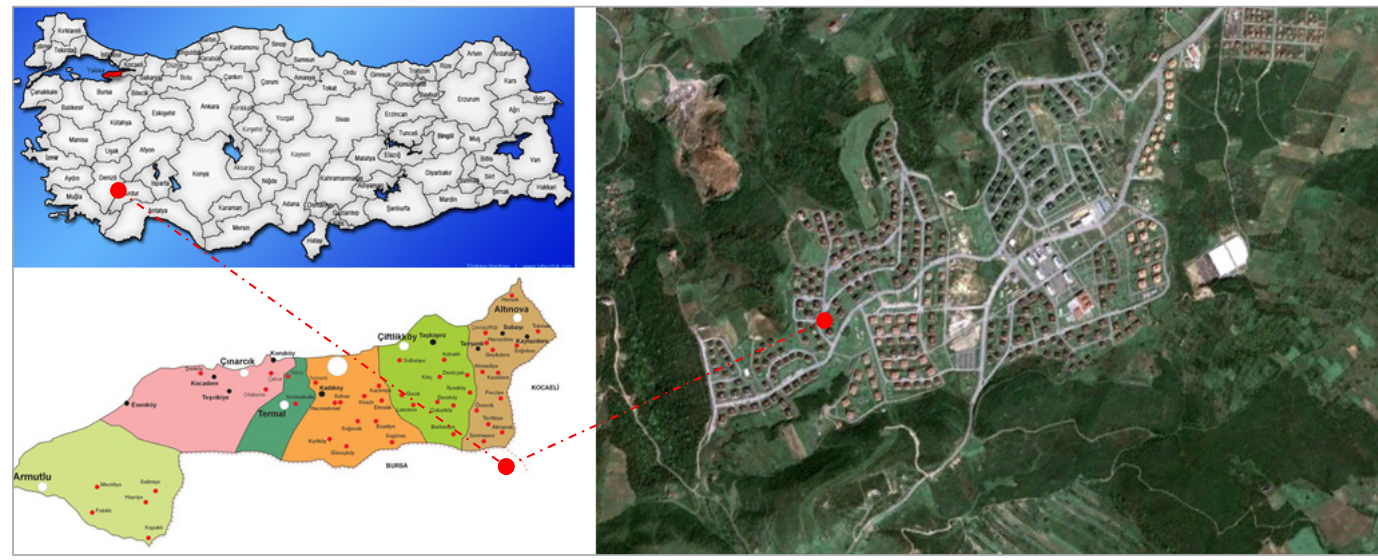

\section{Methodology}

Fig. 2

Map of Turkey showing the location of Subaşı permanent residences site plan 
12.685 houses and 1.881 workplaces were slightly damaged (Ozmen, 2000). Fig. 3 shows the earthquakes around Yalova between the years 1900 and 2013.

Fig. 3

Earthquakes around Yalova between the years 1900 and 2013

(Source: Kurt ve Haybat, 2014)

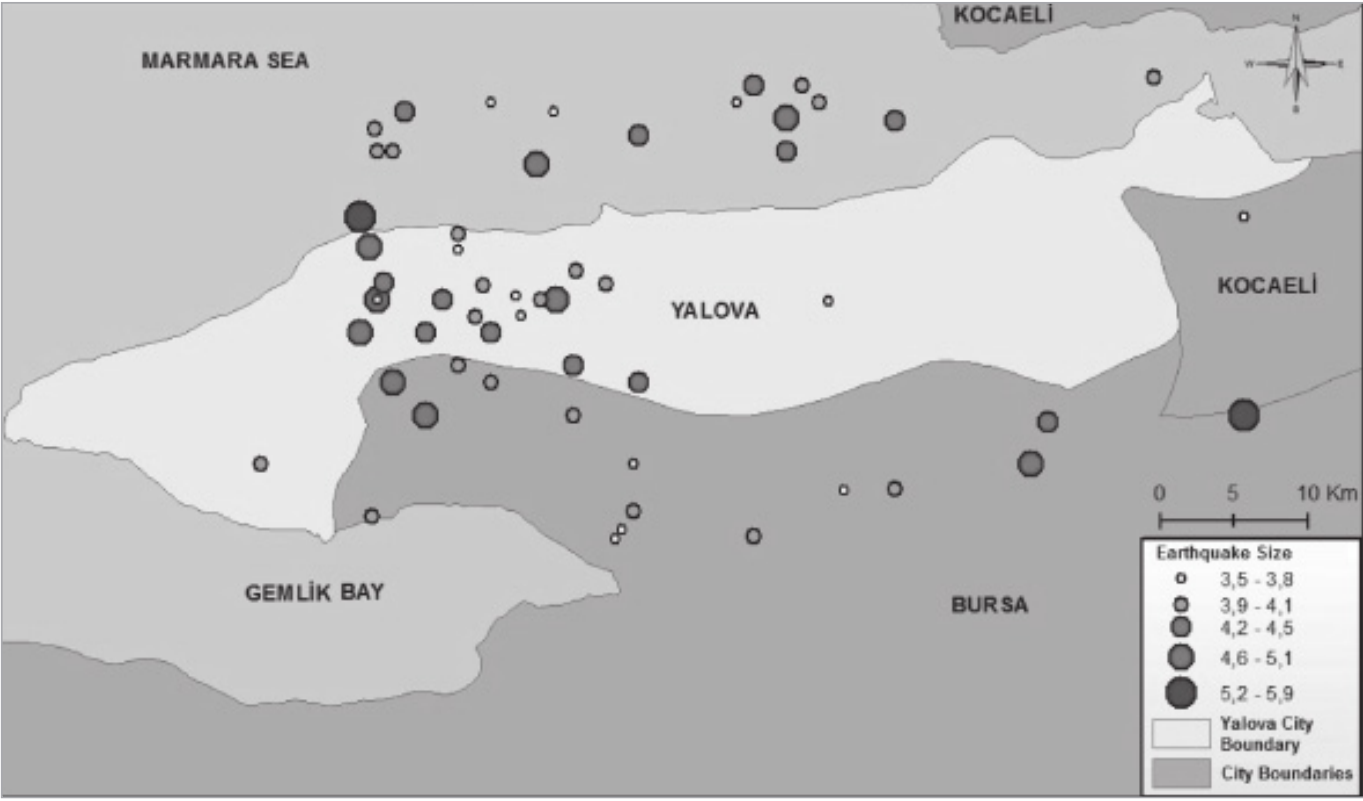

Following the earthquake, the Turkish administration started to tackle housing regeneration to provide units to homeowners (Ganapati, 2013). Subsequently, the Project Management Unit was set up for the construction of the permanent houses supported by external sources (Tas et al., 2011). After the quake, a total of 43,053 permanent houses were constructed in different provinces and districts, in 27 various settlement areas (18 of Turkey's Ministry of Public Works and Settlement, the remaining 9 of the Prime Ministry Project Implementation Unit) (Tas et al., 2011; Erten, 2003). In Subaşı, Yalova 3002 permanent houses were constructed to settle 12.000 people.

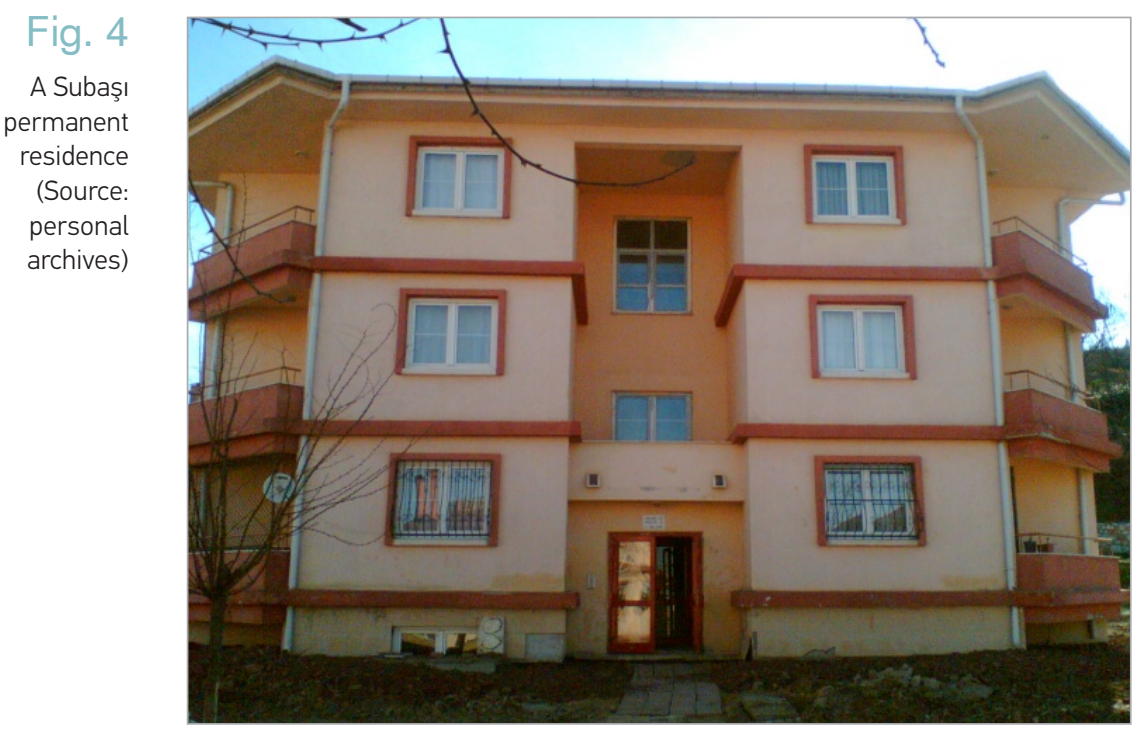

While six housing types were built after the Marmara earthquake, only two different housing types were constructed in Subaşı. The former model has 12 units, and the latter has 6. A photo from Subasi permanent apartments is shown in Fig. 4. Both block prototypes are comprised of a ground floor and two floors, $95 \mathrm{~m} 2$ residential area, three rooms, and one living room. 
The contract for the projects was on 16 06 2000. The area was delivered to the constructors by the Ministry of Public Works and Settlement on 28062002. Hence, the dwellings, which are planned to be finished in about five months, can be completed in about nine months from the place of delivery. Finally, 3002 houses were built in Subasi. Fig. 5 shows a floor plan of the permanent residences.

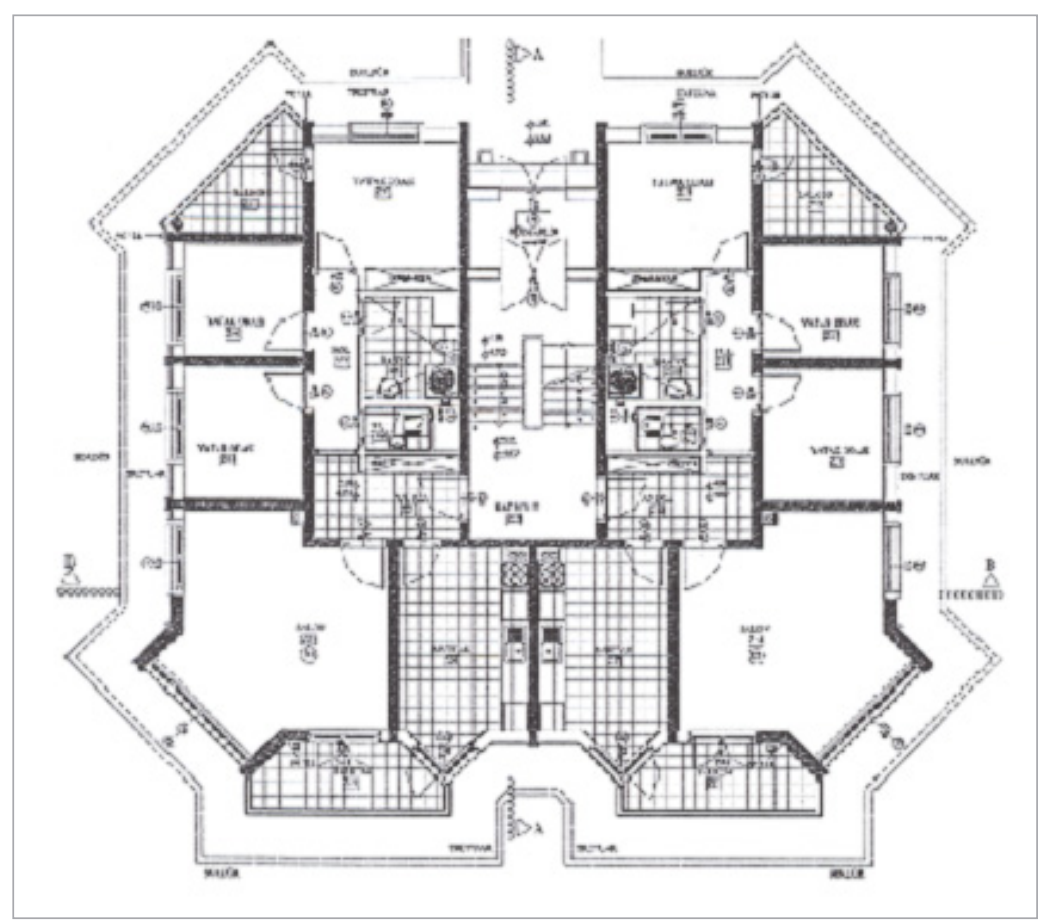

In the study, the demographic characteristics of the participants, such as the number of people in the household, the average monthly income were gathered. Also, thoughts about earthquake resistance, interior size, indoor locations, also needed places, redundant areas, privacy, warming, transportation, neighborhood relations, the presence of green space, missing facilities, the desired location and questions about general services were asked. At first, the participants answered questions about demographic characteristics and pre-earthquake housing. According to the results of the study, the participating families consisted of $2(35.3 \%)$ and $4(23.5 \%)$ people. According to the majority of respondents have earnings between $1000 \mathrm{TL}$ and $1900 \mathrm{TL}$ (equivalent to US\$ 187.68- US\$ 356.59) (Url-2). Before the earthquake, they principally lived in the middle of Altinova subprovince which is at the center of the Yalova province. Pre-earthquake housing was mostly $(64.7 \%)$ apartment buildings. The extent of the pre-earthquake dwellings was mainly among $100-130 \mathrm{~m} 2(41.2 \%)$ and $80-100 \mathrm{~m} 2$ (29.4\%). $76.5 \%$ of the participants were owners of the pre-earthquake residence. The apartments were severely damaged (52.9\%) or destroyed (41.2) in the quake.

Some of the families inhabiting in Subasi permanent housing come from Yalova and some from Central and Eastern Black Sea Region of Turkey. All participants were satisfied with the location of their previous housing. Nearly all participants were satisfied with the size and the place of their previous home.

When asked to the participants about earthquake resilience of their permanent residences, $94.1 \%$ of the households think that their houses are resilient. In the evaluations on the size of the interiors, the participants are satisfied with living room (88.2\%), rooms (41.2\%), kitchen (82.4\%), bathroom $(94.1 \%)$, toilets $(94.1 \%)$, and balconies $(58.8 \%)$. When asked about the location of permanent residences, they are satisfied with living room (\%82.4), rooms (94.1\%), kitchen (82.4\%), bathroom (88.2\%), toilets (94.1\%), balconies (70.6\%).

The participants indicated that they need a storehouse (58.8\%), and a big bathroom (5.9\%). Some said that there is no need for extra space (35.3\%). Most of the items they could bring from their old
Fig. 5

A floor plan of Subaşı permanent houses (Source: personal archives)

\section{Survey Results}


houses (70.6\%) were appropriate to fit into permanent housing. Participants often wanted to live in their previous houses (82.4\%) if there were any possibility.

$88.2 \%$ of the families believe that visible confidentiality was realized between residences while $70.6 \%$ of them believe that no audible isolation was provided. More than half of the participants expressed that (70.6\%) are not satisfied with warming. 64.7\% of them responded that they are satisfied with lighting and ventilation. Nearly all respondents do not complain about fitment. Half of them have got difficulties to go to the city center. $94.1 \%$ of the participants have entrance to the city or district center by minibus. More than half of the participants are going to the city center rarely, the others almost every day.

Mainly, most of the respondents said the neighborhood relationships are well. Besides, the percentage of participants who endure their conversation with their kin and friends are low. Meetings with neighbors to solve problems are very low at $5.9 \%$. Nearly half of them is satisfied with the green areas. All respondents said that there is a need for a hospital in the precinct.

Similarly, the participants also stated that there is a demand of shopping center (47.1\%), business center (41.2\%), entertainment center (52.9\%), mosque (29.4\%) and sports hall (52.9\%) in the location. All the participants noted that the waste is not taken in time. So, they are mostly (82.4\%) not satisfied with the municipality services.

In general, all of the participants were satisfied with the location and size of their old houses. However, almost half of the permanent residences do not like the size of the rooms and balconies of the permanent housing. They are not satisfied with the location of the balconies. The most important reason for this is that there is no user participation in the planning phase of the project. In permanent residences, they need a separate area such as a warehouse. The point that residential structures do not have flexible designs does not allow the housing units to be converted into viable needs. Houses do not hold the chance to enlarge if demanded. It is an essential problem for families who want to experience old living conditions and comfort.

Most of the participants could be able to fit their old belongings in their permanent residences. It can be said that this situation is caused by necessity when the losses of the people whose houses are destroyed are taken into consideration in the economic conditions after the earthquake. Satisfied with visual privacy, participants experience problems with auditory privacy and the heating system of the house. The main reason for this is the permanent housing construction system. The houses were built with a tunnel formwork system for quick completion. As a result, auditory problems occurred in buildings. The state, which was under pressure to relocate the people whose houses were destroyed after the earthquake, wanted to construct the houses as soon as possible. As a result, the houses have been built more rapid and economical in construction methods, thus resulted in a compromise on quality.

One of the most critical problems in permanent housing is the transportation problem. The distance of the area to the city center is an essential problem for the households who want to maintain their old habits. The distance provides a living for the households below the old living standards. In this sense, permanent residences do not provide the expected benefits.

On the other hand, problems have also emerged in the social relations of people settled in permanent residences after a physically destructive earthquake. For instance, in case of a collective decision to solve the problems in the building, adequate communication with the neighbors cannot be ensured, and participation in the meeting is insufficient. There is also a decrease in the relations and communication of the participants with their relatives. Besides, participants are not satisfied with the amount of green space in permanent residences, which are more rural than in the city center. The participants think that the municipality does not provide adequate services to permanent residences. However, the presence of municipal services has vital significance for improving the quality of life of people residing in permanent residences. 
Fig. 6 shows the overall satisfaction with the factors related to the survey. In general, participants have definite opinions about their new houses on earthquake resistance, size, and location of residential interiors, visual privacy, and lighting, Additionally, they have negative thoughts about auditory privacy, heating, transportation to the city center, relations with relatives, problem-solving with neighbors, municipal services. These findings suggest that the permanent residences produced for the people who suffered from the earthquake have not been able to meet the needs of the households sufficiently.

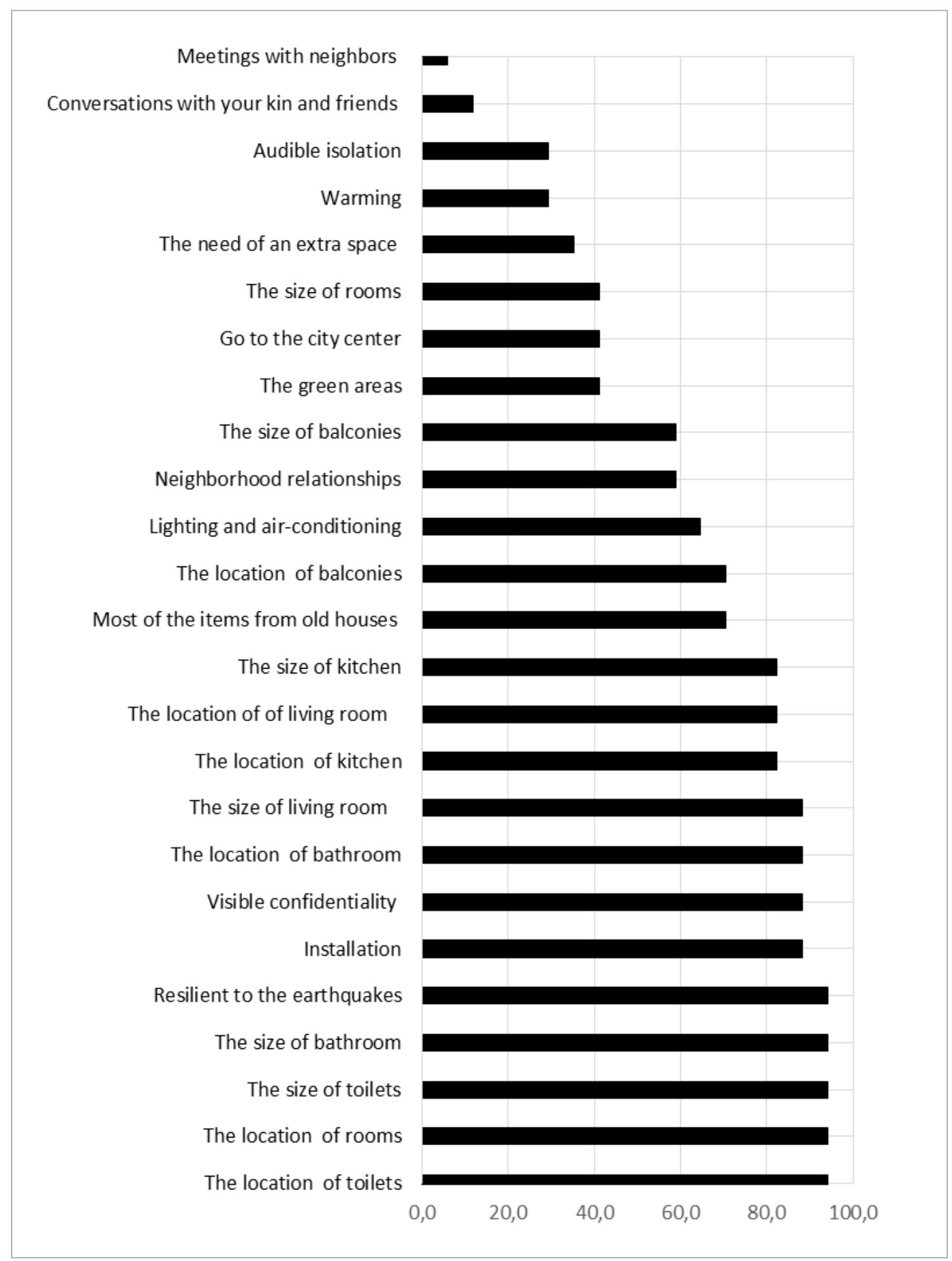

Fig. 6

Overall comparison of the factors 
Disasters are one of the most critical issues to deal with. Various rehabilitative studies are carried out for families affected by disasters to return to normal living conditions. Central and local governments have initiated many activities to prevent specific problems such as housing related to disasters. One of the regenerative actions of the governments is to construct post-disaster housing after a catastrophic disaster. Post-disaster housing is essential to vulnerable families so that all will be capable of returning to a suitable living condition as before the disaster.

Nevertheless, as permanent houses are built very fast, it is crucial that the living standard of permanent housing should be suitable with the prior usage of the users. In this sense, post-use evaluations of permanent housing are getting a value to understand the issue. Within the scope, permanent residences in Subaşı Village, Yalova Province in Turkey have been reviewed in the study. This study was aimed to determine the characteristics that contribute to user satisfaction in the selected area. In doing so, a survey was carried out in the field, and user satisfaction was tried to be revealed. After the survey, some results emerged to evaluate the permanent residences on the area.

One of the most important results of the study is that the post-disaster houses in Subası cannot unite with the existing city, thus reducing the quality of life of the householders. The householders have had to adapt to a different culture, even within the same city. For this reason, it is inevitable to build permanent housing areas in the process of integration with the existing city in the broader frame.

More significantly, the affected householders could not have the opportunity to participate in the project during the planning and design phases. Houses have not been created in a way to answer the real needs of users. It means that the needs of households have not been appropriately addressed during the planning and design of houses. Accordingly, user participation in residential planning after a disaster is a crucial requirement for future housing projects.

In conclusion, looking at the results of the study from a broad perspective, it can be said that any mistakes made in the planning stage of the post-disaster housing cause dilemmas in practice. In this regard, it is necessary to evaluate the subject holistically so that the permanent houses do not create new problems for the despairing households. ter Housing: Yalova Subasi Case presented at the 5th International Conference S.ARCH-2018. The author wishes to thank the respondents who helped him in the survey.

\section{References}

AFAD, Explanatory disaster management terms dictionary, Disaster and Emergency Management Authority, Ankara, Turkey, 2014.

Erten, $G$, What is the place of quake housings in our design and planning culture?, Mimarlık, 309, (2003), 48.

FEMA, A Housing recovery strategy for a new Madrid Earthquake, Draft report of the housing recovery working group, A FEMA / Federal - CUSEC Initiative, USA, 1998.

Freeman, P. K., Allocation of post-disaster reconstruction financing to housing, Building Research and Information, 32, (2004), 5, pp. 427-437. https://doi. org/10.1080/0961321042000221016
Ganapati, N. E., Measuring the processes and outcomes of post-disaster housing recovery: lessons from Gölcük, Turkey, Nat. Hazards, 65, (2013), 3, pp. 1783-1799. https://doi.org/10.1007/s11069-0120442-8

Kurt, S., and Haybat, H., Evaluation of location selection in yalova in terms of geomorphologic features and natural risks, Urban and Urbanization, pp. 673-688. Efe, R., Onay, T.T., Sharuho, I., Atasoy, E. (Eds.), St. Kliment Ohridski University Press, Sofia, Bulgaria, ISBN: 978-954-07-3772-0, 2014.

Limoncu, S. and Bayulgen, C., Türkiye'de afet sonrası yaşanan barınma sorunları, YTU Faculty of Ar- 
chitecture E-Journal, 1, (2005), 1, pp. 18-27.

Marka, Yalova investment report, Eastern Marmara Development Agency, Kocaeli, Turkey, 2010.

Mukherji, A., From tenants to homeowners: housing renters after disaster in Bhuj, India, Housing Studies, 30, (2015), 7, pp. 1135-1157. https://doi.org $/ 10.1080 / 02673037.2015 .1008423$

Ozmen, B., Damages of 17 August 1999 İzmit Gulf Earthquake, Turkish Earthquake Foundation, Ankara, Turkey, 2000.

Oztekin, K. and Yıldırım, S.T., Building, constructed regions and the earthquake in Kocaeli, e-Journal of New World Sciences Academy Natural and Applied Sciences, 2, (2007), 1, pp. 22-29.

Pampal, S. and Ozmen, B., Earthquakes are natural disasters? - to cope with earthquakes, Efil Yayınevi Yayınları, Ankara, Turkey, 2015.

Tas, N., Cosgun, N. And Tas, M., A qualitative evaluation of the earthquake permanent housings in Turkey in terms of user satisfaction-Kocaeli, Gun- dogdu Permanent Housing model, Building and Environment, 42, (2007), 9, pp. 3418-3431. https://doi. org/10.1016/j.buildenv.2006.09.002

Tas, N., Tas, M. and Cosgun, N., Permanent housing production process after 17 August 1999 Marmara Earthquake in Turkey, International Journal of Strategic Property Management, 15, (2011), 3, pp. 312-328. https://doi.org/10.3846/1648715X.2011.617863

UN, Shelter after disaster: guidelines for assistance, Office of the United Nations Disaster Relief Coordinator (UNDRO), United Nations, New York, USA, 1982.

Url-1, http://sgdd.org.tr/wp-content/uploads/ 2017/06/Yalova.pdf, data retrieved 26.03.2018.

Url-2, http://paracevirici.com, date retrieved 07.01.2019.

Yamalı, M. S., Akgün, Y. and Karaveli, A. S., An evaluation of emergency accommodation units after earthquake, The Third International Conference on Earthquake Engineering and Seismology, İzmir, Turkey, 2015, pp.

\section{ALPER BODUR}

\section{About the

Asst. Prof. Dr.

Ondokuz Mayıs University, Faculty of Architecture

\section{Main research area}

Disaster management, post disaster housing, social housing, building sciences, fire safety.

\section{Address}

Faculty of Architecture, Ondokuz Mayıs University,

Guzel Sanatlar Kampusu, Ilkadim, 55139 Samsun, Turkey.

Tel. +903623121919 / 4768

E-mail: boduralper@yandex.com 